\title{
Current Challenges in Statistical Seismology
}

\author{
Qinghua Huang, ${ }^{1}$ Matthew Gerstenberger,${ }^{2}$ and Jiancang Zhuang ${ }^{3}$
}

\section{Introduction}

Statistical seismology is a subject that aims to bridge the gap between physical and statistical models (Vere-Jones et al. 2005). It has developed rapidly during the last several decades and has been highlighted every 2 years by the International Workshop on Statistical Seismology (StatSei). This workshop has now been held nine times in many different countries around the globe. Several past special volumes related to seismicity analysis and earthquake statistics have been developed based on the StatSei and related workshops (e.g., Vere-Jones et al. 2005; RHOADES et al. 2010; TSAKLIDS et al. 2011; Console et al. 2012; Papadopoulos 2012). In this issue, we have collected articles following the 8th International Workshop on Statistical Seismology (StatSei8: http://www.geophy.pku.edu.cn/statsei8/) which was held in Beijing, China, in 2013.

Many significant achievements have been accomplished during last several decades. One is the formulation of conditional intensity models for quantifying time-varying seismicity rates. A particular example of this is the ETAS model developed by Ogata (1988). It has become a de facto standard model, or null hypotheses, for other models and ideas to be compared to. An advantage of using conditional intensity models is that the evaluation of their forecasting performance can be done in a measured and statistical way using the framework of probability gain. This means that improvements in understanding

1 Department of Geophysics, School of Earth and Space Sciences, Peking University, Beijing 100871, China. E-mail: huangq@pku.edu.cn

2 GNS Science, Lower Hutt, New Zealand.

3 Institute of Statistical Mathematics, Tokyo 1908562, Japan. of earthquake clustering can be quantified by developing new ideas into models and then comparing them to ETAS, or other models, using statistical hypothesis testing. Ultimately, rigorous testing of forecast models is necessary in order to improve our ability to forecast seismic hazard (JORDAN et al. 2011).

Both probabilistic earthquake forecasting and binary earthquake prediction are some of the most challenging problems in the subject of geophysics. Currently, many scientists believe that individual earthquakes cannot be deterministically predicted (e.g., Geller et al. 1997) due to our inability to observe many of the fundamental processes of the system and also its inherent randomness. Therefore, in order to best quantify our state of knowledge, the statistical seismology community has placed a larger focus on probabilistic forecasting. In order to provide more reliable earthquake forecast models, the challenge is to construct models that can give increased information gain with respect to a reference model, such as ETAS or complete randomness. This requires not only increased understanding of the physical process of earthquakes, such as the preparation and rupture processes of the earthquake source and the interaction between earthquakes and tectonic environments, but also development and implementation of improved statistical methods for testing and validating physical hypotheses based on observed data.

With rapid development of observation technologies, more and more observational data are obtained. For example, GPS observation of surface displacement, InSAR observation of the co-seismic deformation, ionospheric observations, etc., bring statistical seismology into the big data era. Additionally, the understanding of what an earthquake itself is has been extended by the discovery of slow earthquakes, tremors, and VLF earthquakes. These new observations provide new theories and 
approaches to help us understand seismicity. However, there is no free lunch. To make use of these new observations, statistical seismologists are challenged by tasks of developing new methods to analyze these data more efficiently and new models to connect them to the earthquake process and tectonic environments.

This special issue emerged after the recent 8th International Statistical Seismology (StatSei8) workshop in Beijing. The articles within have been collected to report on the exciting new research in statistical seismology methods and applications; the issue contains a collection of the newest methods, techniques and outputs related to statistical analysis of earthquake occurrence and earthquake probability forecasting, and to ultimately helps to define future research directions in the field.

Papers submitted to this topical issue can be loosely categorized into the following topics:

\section{The connection between seismicity and physics In} this class of articles, BeBBington et al. (2016), IwATA (2016), and LePTOKAROPOULOs et al. (2016), tested the seismicity rate of aftershocks or background events after big events, revealing the complexity of the seismicity changes due to the effect of Coulomb stress changes. WANG et al. (2016) evaluate the influence of the 2011 M9 Tohoku-Oki mega earthquake on the seismicity in eastern China. ZHANG (Shenjian) et al. (2016a) and ZHANG (Shengfeng) et al. (2016b) discussed the b-value changes before and after the Wenchuan earthquakes and explain such variation by changes in the stress field and fault healing.

2. Data quality Seismology is often an observational scientific subject and research in the field is dependent on not only the availability of high-quality data, but also on a thorough understanding of what the data quality is. PANZERA et al. (2016) provided a revised Iceland catalog, which is extremely useful for analyzing seismicity in this region. Mignan and CHEN (2016) showed the detected seismicity scaled in space in the Taiwan region.

3. Statistical analysis of seismicity In that category, CHEN and SHEARER (2016b) compared the foreshocks in the California region and in ETAS synthetic catalogs. Li et al. (2016); TELESCA et al. (2016); and SARLIS et al. (2016) analyzed seismicity in different regions around the world by using different statistical methods. For example, Li et al. (2016) used the $p$ value and $\mathrm{K}-\mathrm{S}$ statistics as goodness-of-fit test in estimating the completeness magnitude threshold. Different from other papers in this category, FORD and LABAK (2016) analyzed the aftershock activity due to underground nuclear explosions.

4. Seismicity-based probability forecasting of seismicity and seismic hazard evaluation Articles in this category focus on developing statistical models and methods for earthquake forecasts. Yu et al. (2016); Zhang et al. (2016c); and ChANG et al. (2016) discussed two forecast algorithms, PI and LURR, and their applications. Wu et al. (2016) developed a probability model where seismicity rate depends on quiescence and activation of small earthquakes. NAvA et al. (2016) discussed the application of the Bayesian estimate and forecast procedures to a semi-periodic model, while BAYRAK and TÜrKER (2016) illustrated how to use Bayesian estimates to evaluate seismic hazard.

5. Alternative datasets and testing of precursors This class of articles moves beyond using only observed seismicity and attempts to find correlations between precursory non-seismic observations and seismicity, with a potential outcome of improved earthquake forecasting models. Fusinawa and Noda (2016); Jiang et al. (2016) studied the correlation between the seismoelectric wave field and the occurrence of earthquakes. Using the Molchan error diagram, Eleftheriou et al. (2016) and CHen et al. (2016a) evaluate the precursory information in the thermal infra-red spectrum emitted by the Earth and in the observation of mobile gravity fields, respectively.

In all papers presented, a good understanding of both the physical and statistical aspects of the problems investigated is necessary. To improve our understanding of how the Earth works, it is necessary to couple our understanding of the physics of the process with robust statistical methods. Doing so, and understanding the uncertainties involved will ultimately help address the important demands in seismology and the social and engineering sciences; importantly this includes the testing of models of earthquake forecasts, earthquake early warning, and 
seismic hazard assessments. Statistical seismology has presented many challenges to statisticians and geophysicists, but there are undoubtedly many more exciting discoveries yet to come.

\section{REFERENCES}

BAYRAK Y and T Türker (2016) The Determination of Earthquake Hazard Parameters Deduced from Bayesian Approach for Different Seismic Source Regions of Western Anatolia. Pure Appl Geophys (This issue).

Bebbington M, D Harte and C Williams (2016) Cumulative Coulomb stress triggering as an explanation for the Canterbury (New Zealand) aftershock sequence: Initial conditions are everything? Pure Appl Geophys (This issue).

Chang LY, CC Chen, YH Wu, TW Lin, CH Chang and CW Kan (2016) A strategy for a routine pattern informatics operation applied to Taiwan. Pure Appl Geophys (This issue).

CHEN S, CS JiAng and JC ZhuAng (2016) Statistical evaluation of efficiency and possibility of earthquake predictions with gravity field variation and its analytic signal in western China. Pure Appl Geophys (This issue).

CHEN XW and PM SHEARER (2016) Analysis of foreshock sequences in California and implications for earthquake triggering. Pure Appl Geophys (This issue).

Console R, K YAmaoka and J Zhuang (2012) Implementation of Short- and Medium-Term Earthquake Forecasts. Int J Geophys, 217923. doi:10.1155/2012/217923.

Eleftheriou A, C Filizzola, N Genzano, T Lacava, M Lisi, R Paciello, N Pergola, F Vallianatos and V Tramutoli (2016) Long term RST analysis of anomalous TIR sequences in relation with earthquakes occurred in Greece in the period 2004-2013. Pure Appl Geophys (This issue).

FoRD SR and P LABAK (2016). An Explosion Aftershock Model with Application to On-Site Inspection. Pure Appl Geophys (This issue).

Fujinawa Y and Y Noda (2016) Characteristics of seismoelectric wave fields associated with natural microcracks. Pure Appl Geophys (This issue).

Geller RJ, DD JACKson, YY Kagan and F Mulargia (1997) Earthquakes cannot be predicted. Science, 275 (5306), 1616.

Iwata T. (2016) A variety of aftershock decay in the rate-and state-friction model due to the effect of secondary aftershocks: Implications from real aftershock sequences. Pure Appl Geophys (This issue).

Jiang F, XB Chen, Y Zhan, GZ Zhao, H Yang, LQ Zhao, L Qiao and LF WANG (2016) Shifting correlation between earthquakes and electromagnetic signals: a case study of the 2013 MinxianZhangxian ML6.5 (MW6.1) earthquake in Gansu, China. Pure Appl Geophys (This issue).

Jordan TH, Y-T Chen, P Gasparini, R Madariaga, I Main, W Marzocchi, G Papadopollos, G Sobolev, $\mathrm{K}$ Yamaoka and $\mathrm{J}$ ZsCHAU (2011) Operational earthquake forecasting: state of knowledge and guidelines for implementation. Annals Geophysics, 54 (4), 316-391.

Leptokaropoulos KM, EE Papadimitriou, B Orlecka-Sikora and VG Karakostas (2016) Evaluation of Coulomb Stress Changes from Earthquake Productivity Variations in Western Corinth Gulf, Greece. Pure Appl Geophys (This issue).

Li HC, CH CHANG and CC CHEN (2016) Quantitative analysis of seismicity before Large Taiwanese Earthquakes Using G-R Law. Pure Appl Geophys (This issue).

Mignan A and CC Chen (2016) The spatial scale of detected seismicity. Pure Appl Geophys (This issue).

Nava FA, CB Quinteros, E Glowacka and J Frez (2016) A Bayesian Assessment of Seismic Semi-Periodicity Forecasts. Pure Appl Geophys (This issue).

Ogata Y (1988) Statistical models for earthquake occurrences and residual analysis for point processes (in Applications). J Am Stat Associ, 83 (401), 9-27.

Panzera F, JD Zechar, KS VogfJörd and DAJ Eberhard (2016) A revised earthquake catalogue for South Iceland. Pure Appl Geophys (This issue).

Papadopoulos G. (editor) (2012). 7th International Workshop in Statistical Seismology, 2011. Res Geophys, 2 (1).

Rhoades D, M Savage, E Smith, M Gerstenberger and D VereJones (2010) Introduction. Special Issue: Seismogenesis and Earthquake Forecasting: the Frank Evison Symposium. Pure Appl Geophys, 167, 619-621.

Sarlis NV, ES Skordas, S-R G Christopoulos and PA Varotsos (2016) Statistical significance of the minimum of the order parameter fluctuations of seismicity before major earthquakes in Japan. Pure Appl Geophys (This issue).

Telesca L, M Lovallo, SK Aggarwal, PK Khan and BK Rastogi (2016) Visibility graph analysis of 2003-2012 earthquake sequence in Kachchh region, Western India. Pure Appl Geophys (This issue).

Tsaklids GM, EE PAPAdimitriou and N Limnios (2011) Statistical tools for earthquake and mining seismology: preface to the topical issue. Acta Geophysica, 59, 657-658. doi: 10.2478/ s11600-0022-4.

Vere-Jones D, Y Ben-Zion and R Zuniga (2005) Statistical seismology. Pure Appl Geophys, 162 (6-7), 1023-1026.

WANG LF, J Liu, J ZHaO and JG Zhaо (2016) Tempo-spatial impact of the 2011 M9 Tohoku-Oki earthquake on Eastern China. Pure Appl Geophys (This issue).

Wu YH, CC CHEN and HC Li (2016) Conditional probabilities for Large Events Estimated by Small Earthquake Rate. Pure Appl Geophys (This issue).

Yu HZ, FR Zhou, QY Zhu, XT Zhang and YX Zhang (2016) Development of a combination approach for seismic hazard evaluation. Pure Appl Geophys (This issue).

Zhang SJ and SY Zноu (2016) The spatial and temporal variation of the b-value in Southwest China. Pure Appl Geophys (This issue).

Zhang, SF, ZL Wu and CS JiAng (2016) The central China NorthSouth Seismic Belt: Seismicity, Ergodicity, And Five-Year PI Forecast in Testing. Pure Appl Geophys (This issue).

ZHANG SF, ZL Wu and CS JIANG (2016) Signature of fault healing in an aftershock sequence? The 2008 Wenchuan earthquake. Pure Appl Geophys (This issue). 